OAK RIDGE NATIONAL LABORATORY

MARTIN MARIETTA

\title{
Technical Support Section Instrument Support Program for Nuclear and Nonnuclear Facilities with Safety Requirements
}

\author{
Revision 2 \\ Supersedes ORNL/TM-10846/R1 \\ B. P. Adkisson \\ K. L. Allison
}

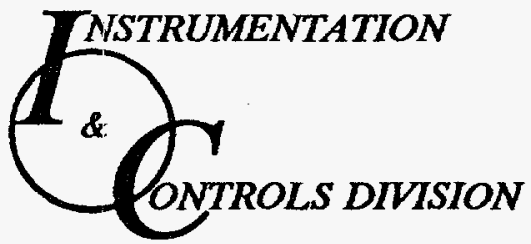

MASTER 
This report has been reproduced directly from the best available copy.

Available to DOE and DOE contractors from the Office of Scientific and Technical Information, P.O. Box 62, Oak Ridge, TN 37831; prices available from (615) 576-8401, FTS 626-8401.

Available to the public from the National Technical Information Service, U.S. Department of Commerce, 5285 Port Royal Rd., Springfield, VA 22161.

This report was prepared as an account of work sponsored by an agency of the United States Government. Neither the United States Government nor any agency thereof, nor any of their employees, makes any warranty, express or implied, or assumes any legal liability or responsibility for the accuracy, completeness, or usefulness of any information, apparatus, product, or process disclosed, or represents that its use would not infringe privately owned rights. Reference herein to any specific commercial product, process, or service by trade name, trademark, manufacturer, or otherwise, does not necessarily constitute or imply its endorsement, recommendation, or favoring by the United States Government or any agency thereof. The views and opinions of authors expressed herein do not necessarily state or reflect those of the United States Government or any agency thereof. 
ORNL/TM-10846/R2

Instrumentation and Controls Division

TECHNICAL SUPPORT SECTION

INSTRUMENT SUPPORT PROGRAM FOR NUCLEAR AND NONNUCLEAR

FACILITIES WITH SAFETY REQUIREMENTS

B. P. Adkisson

K. L. Allison

January 1995

Prepared by

OAK RIDGE NATIONAL LABORATORY

Oak Ridge, Tennessee 37831-6285

managed by

MARTIN MARIETTA ENERGY SYSTEMS, INC.

for the

U.S. DEPARTMENT OF ENERGY

under contract DE-AC05-84OR21400 



\section{APPROVAL}

The requirements, procedures, and responsibilities documented in ORNL/TM-10846/R2, Technical Support Section Instrument Support Program for Nuclear and Nonnuclear Facilities with Safety Requirements, are approved by:

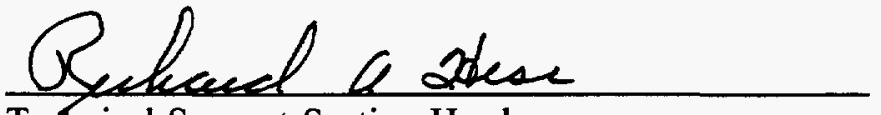

Technical Support Section Head, Instrumentation and Controls Division

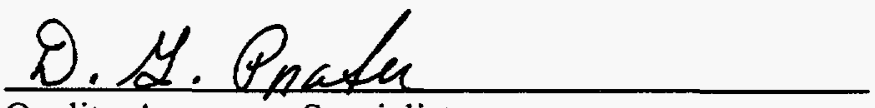

Quality Assurance Specialist, Instrumentation and Controls Division

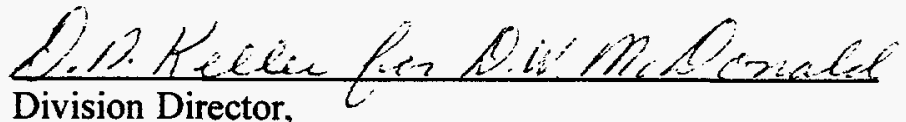
Instrumentation and Controls Division

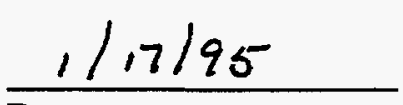

Date

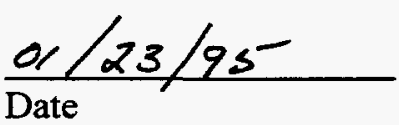

Date

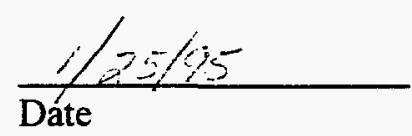





\section{CONTENTS}

Page

DEFINITIONS OF TERMS USED IN THIS DOCUMENT $\ldots \ldots \ldots \ldots \ldots \ldots \ldots$ vii

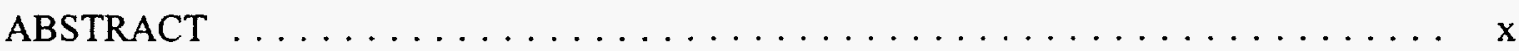

1. INTRODUCTION $\ldots \ldots \ldots \ldots \ldots \ldots \ldots \ldots \ldots \ldots \ldots \ldots \ldots \ldots \ldots$

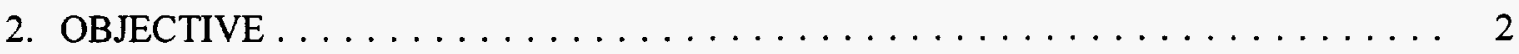

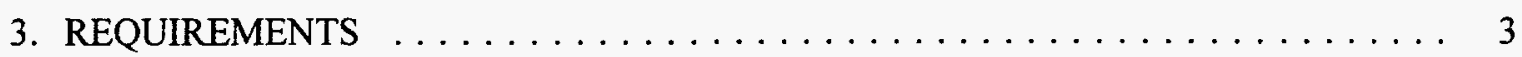

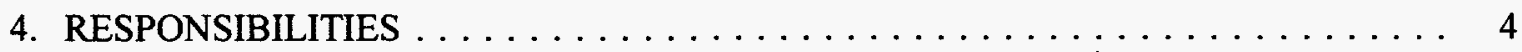

4.1 TECHNICAL SUPPORT SECTION HEAD $\ldots \ldots \ldots \ldots \ldots \ldots \ldots \ldots \ldots$

4.2 TECHNICAL SUPPORT SECTION TSR/OSR/LCD PROGRAM

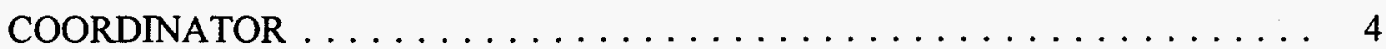

4.3 GENERAL SUPERVISORS $\ldots \ldots \ldots \ldots \ldots \ldots \ldots \ldots \ldots \ldots \ldots \ldots$

4.4 SUPERVISORS ......................... 5

5. PROCEDURES FOR DEVELOPING TECHNICAL SUPPORT

SECTION TSR, OSR, OR LCD INSTRUMENT FACILITY PLANS $\ldots \ldots \ldots \ldots .7$

5.1 INSTRUMENT FACILITY PLANS $\ldots \ldots \ldots \ldots \ldots \ldots \ldots \ldots \ldots \ldots$

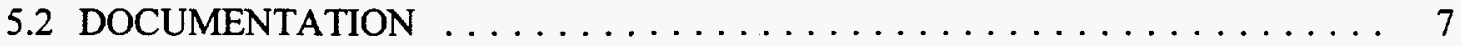

5.3 INSTRUMENT DESIGNATION AND LABELING $\ldots \ldots \ldots \ldots \ldots \ldots \ldots \ldots$

5.3.1 Safety System Instrument Labeling $\ldots \ldots \ldots \ldots \ldots \ldots \ldots \ldots$

5.3 .2 Limiting Condition Instrument Labeling . . . . . . . . . . . 8

5.3.3 Safety System and Limiting Condition Instruments

in Hazardous Environments Labeling . . . . . . . . . . . . . . 9

5.4 INSTRUMENT IDENTIFICATION IN THE MAINTENANCE

ACCOUNTABILITY, JOBS, AND INVENTORY CONTROL

(MAJIC) SYSTEM . . . . . . . . . . . . . . . . . . . . 9

5.5 HANDLING OF INSTRUMENTS "ON HOLD" $\ldots \ldots \ldots \ldots \ldots \ldots \ldots \ldots 11$

5.6 REMOVAL OF INSTRUMENTS FROM TSR, OSR, OR LCD SERVICE $\ldots \ldots$. 11

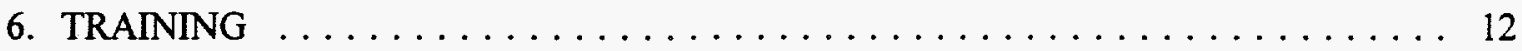

7. TSR, OSR, AND LCD REVIEW PROCEDURES $\ldots \ldots \ldots \ldots \ldots \ldots \ldots \ldots \ldots$

7.1 INSTRUMENT FACILITY PLAN REVIEW OBJECTIVES $\ldots \ldots \ldots \ldots \ldots \ldots$

7.2 ANNUAL REVIEW RESPONSIBILITIES $\ldots \ldots \ldots \ldots \ldots \ldots \ldots \ldots \ldots$

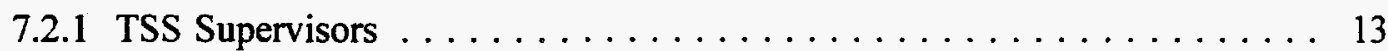

7.2.2 TSS TSR/OSR/LCD Coordinator $\ldots \ldots \ldots \ldots \ldots \ldots \ldots \ldots$

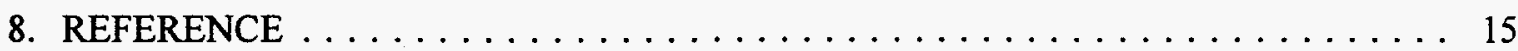

Appendix A. EXAMPLES OF FORMS USED FOR INSTRUMENT FACILITY

PLAN, MAINTENANCE PERSONNEL ASSIGNMENTS,

AND SAFETY INSTRUMENT LISTING FOR OSRs 



\section{DEFINITIONS OF TERMS USED IN THIS DOCUMENT}

Configuration Management (of Safety Class Items). A process to ensure that (1) functional and physical characteristics are documented for components, structures, and systems required for safety or that could affect safety as identified in the Safety Analysis and Review Program; (2) changes to required systems are identified, controlled, and approved by authorized persons; and (3) the identification process and the change process are documented.

Facility Manager (or Designee). The technically competent individual who has direct line responsibility for a facility's or group of related facilities' operations, including authority to direct physical changes to the facility (see ORNL SPP X-GP-12).

Health and Safety Review Committee(s). The standing review committee(s) or ad hoc committee(s) designated by a committee charter, the Oak Ridge National Laboratory (ORNL) director or deputy director, or the Office of Operational Readiness and Facility Safety to review safety analyses, preliminary safety analysis reports, final safety analysis reports, and operational safety requirements, as well as conduct preoperative and periodic facility reviews. (Ad hoc committees appointed by the ORNL deputy director may perform special reviews.)

Limiting Conditions Document (LCD). The document that defines the conditions, safe boundaries, and bases thereof along with the management control required to ensure safe operation of low, generally acceptable, or radiological classified nonnuclear facilities.

Limiting Conditions for Operation (LCOs). Those administratively established constraints on equipment and operational characteristics that shall be adhered to during operation of the facility. The LCOs are the lowest functional capability for performance level required for operation of the facility.

Limiting Control Settings (LCSs). The minimum capabilities or performance levels of equipment or administrative controls that prevent reaching safety limit values and are required for safe operation of the facility (formerly called limiting safety system settings).

Nonreactor Nuclear Facility. Those activities or operations that involve radioactive and/or fissionable materials in such form and quantity that a nuclear hazard potentially exists to the employees or the general public. Included are activities or operations that

- produce, process, or store radioactive liquid or solid waste, fissionable materials, or tritium;

- conduct separations operations; 
- conduct irradiated materials inspection, fuel fabrication, decontamination, or recovery operations;

- conduct fuel enrichment operations; or

- perform environmental remediation or waste management activities involving radioactive materials.

Incidental use and generating of radioactive materials in a facility operation (e.g., check and calibration sources, use of radioactive sources in research and experimental and analytical laboratory activities, electron microscopes, and X-ray machines) would not ordinarily require the facility to be included in this definition. Accelerators and reactors and their operations are not included. The application of any rule to a nonreactor nuclear facility is applied by using a graded approach.

Nuclear Facility. Refers to reactor and nonreactor nuclear facility.

Office of Operational Readiness and Facility Safety. The representatives of the Laboratory director and deputy director for facility safety. The manager of this office is designated as the installation facility safety manager (IFSM).

Operational Safety Requirements (OSRs). The requirements that define the conditions, safe boundaries, and bases thereof along with the administrative control required to ensure the safe operation of high- or moderate-level nonnuclear facilities. Terminology is being replaced by TSRs per DOE Order 5480.22 for nuclear facilities.

Safety Analysis Report (SAR)/Safety Assessment Document (SAD). SARs and SADs (for accelerator facilities) are safety documents that systematically identify hazards associated with a facility; describe and analyze the adequacy of the measures taken to eliminate, control, or mitigate identified hazards; and analyze and evaluate potential accidents and associated risks of operating facilities. Graded SARs (or SADs) are developed on the bases of the results of the Hazard Screening Report for nuclear and significant nonnuclear facilities.

Safety Systems. The equipment and/or hardware that provides a safety function by preventing or mitigating accidents, thus ensuring that the operation of the facility shall not cause unacceptable risk to the safety and health of employees and the public.

Support and Services Divisions. The ORNL organizations that provide support to the divisions that operate nuclear facilities (e.g., the Instrumentation and Controls Division, Plant and Equipment Division, Radiation Protection Surveillance, Fire Department, and Quality Department). 
Surveillance. A deliberate and systematic inspection, test, calibration, or check of equipment to verify continuing safe performance in accordance with established criteria.

Technical Safety Requirements (TSRs). The requirements that define the conditions, safe boundaries, and bases thereof along with the administrative control required to ensure the safe operation of nuclear facilities. OSRs are being replaced by TSRs per DOE Order 5480.22 for nuclear facilities.

Technical Support Section (TSS). The section of the Instrumentation and Controls Division responsible for maintenance and calibration of facility instruments and safety systems. 


\begin{abstract}
This document describes the requirements, procedures, and responsibilities of the Instrumentation and Controls (I\&C) Division's Technical Support Section (TSS) for instruments identified in nonreactor nuclear and nonnuclear facilities at Oak Ridge National Laboratory (ORNL) with Operational Safety Requirements (OSRs) or Limiting Conditions Documents (LCDs). As a result of DOE Order 5480.22 Technical Safety Requirements (TSRs), OSRs, and LCDs for nuclear facilities will be eventually replaced by TSRs. OSRs or LCDs will continue to be required for high-, moderate-, or low-level radiological nonnuclear facilities. Applicable U.S. Department of Energy, Martin Marietta Energy Systems, Inc., and ORNL procedures are referenced.

The objective of this document is to present an instrument surveillance plan for nonreactor nuclear and nonnuclear facility-identified instruments or systems as specified in the facility's OSR, LCD, or TSR. The instrument surveillance plan is a collaborative effort between the facility manager and the I\&C Division TSS staff, thereby ensuring that the surveillance requirements stated in the OSR, LCD, or TSR are fulfilled within the required time frame.
\end{abstract}




\section{INTRODUCTION}

This document describes requirements, procedures, and supervisory responsibilities of the Oak Ridge National Laboratory (ORNL) Instrumentation and Controls (I\&C) Division's Technical Support Section (TSS) for instrument surveillance and maintenance in nonreactor nuclear facilities having identified Operational Safety Requirements (OSRs) or Limiting Conditions Document (LCDs). Implementation of requirements comply with the requirements of U.S. Department of Energy (DOE) Orders 5480.5, 5480.22, and 5481.1B; Martin Marietta Energy Systems, Inc. (Energy Systems), Policy Procedure ESS-FS-201; and ORNL SPP X-ESH-15.

OSRs and LCDs constitute an agreement or contract between DOE and the facility operating management regarding the safe operation of the facility.

One basic difference between OSRs and LCDs is that violation of an OSR is considered a Category II occurrence, whereas violation of an LCD requirement is considered a Category III occurrence (see Energy Systems Standard ESS-OP-301 and ORNL SPP X-GP-13). OSRs are required for high- and moderate-hazard nuclear facilities, whereas the less-rigorous LCDs are required for low-hazard nuclear facilities and selected "generally accepted" operations. Hazard classifications are determined through a hazard screening process, which each division conducts for its facilities.

As a result of the new DOE Order 5480.22, the existing OSRs, Technical Specifications (reactor facilities), and LCDs at ORNL will eventually be replaced by Technical Safety Requirement (TSRs) for nuclear facilities. ORNL management will submit to DOE plans and schedules for bringing existing OSRs, Technical Specifications, and LCDs into compliance with the new order. In the meantime, as stated in ORNL SPP X-ESH-15, ORNL facilities will continue to operate under the existing requirements for OSRs, Technical Specifications, and LCDs.

ORNL Facility Safety (FS) Procedure, FS-2.0, Facility Authorization Bases Documentation, establishes the program to develop and maintain the documentation that spells out the agreement between Energy Systems and DOE. The FS procedure is implemented by ORNL SPP X-ESH-1.

It is intended that affected I\&C Division maintenance staff will join into partnership teams with facility staff. Where possible, I\&C Division staff will seek to understand facility manager program goals and compliance issues to comply with this directive as effectively as possible. 


\section{OBJECTIVE}

The objective of this document is to present the steps for developing a TSS instrument plan for surveillance and maintenance of nonreactor nuclear and nonnuclear facility instrumentation, thereby assisting the facility manager in fulfilling the requirements of the TSR, OSR, or LCD. This document addresses scheduled maintenance and surveillance requirements for components and systems as specified in the OSR, LCD, or TSR. 


\section{REQUIREMENTS}

TSS shall provide the following services for nonreactor nuclear and nonnuclear facilities identified as having OSRs or LCDs.

a. When requested, assist the facility manager in the development and review of TSRs, OSRs, and LCDs.

b. Develop and document an instrument facility plan for identified instruments and systems, and assist the facility manager in implementing a configuration management program.

c. Provide assistance to facility workers in implementing TSR, OSR, and LCD requirements on schedule, and report results to the facility manager.

d. Perform maintenance and surveillance activities to ensure that equipment meets LCSs and LCOs requirements.

e. Ensure that maintenance personnel working in nonreactor nuclear and nonnuclear facilities with safety requirements are trained in generic operational safety topics and are trained in and aware of facility-specific procedures and safety requirements. Personnel training shall be documented and records shall be retained on file as outlined in TSS's training program. 


\section{RESPONSIBILITIES}

\subsection{TECHNICAL SUPPORT SECTION HEAD}

The TSS head shall be responsible for the following tasks.

a. Review requests for service, ensure compliance with the TSR/OSR/LCD instrument program described herein, review and approve revisions to this program, review and approve each TSR, OSR, or LCD instrument facility plan, and implement draft TSRs, OSRs, or LCDs as above when they become available to TSS.

b. Obtain the TSR, OSR, or LCD from the program manager or the facility manager and authorize preparation of a TSR, OSR, or LCD instrument facility plan.

c. Distribute copies of the TSR, OSR, or LCD to the responsible general supervisors and TSR/OSR/LCD program coordinator.

\subsection{TECHINICAL SUPPORT SECTION TSR/OSR/LCD PROGRAM COORDINATOR}

The TSS TSR/OSR/LCD program coordinator shall be responsible for administration of the TSR/OSR/LCD instrument program and perform the following tasks.

a. Act as liaison to the facility manager and the Office of Operational Readiness and Facility Safety (OORFS).

b. Schedule training sessions for maintenance personnel working in nonreactor nuclear and nonnuclear facilities.

c. Ensure systematic documentation of instrumentation, training, and notices or memos concerning each facility.

d. Annually review each TSR, OSR, or LCD instrument facility plan with TSS supervisors involved with the facility, and report the results of this review to the TSS head and appropriate facility supervisor.

e. Triennially review the TSR/OSR/LCD instrument program described herein.

f. Perform effectiveness reviews periodically to ensure a continued and successful TSR/OSR/LCD support function.

\subsection{GENERAL SUPERVISORS}

Each TSS general supervisor shall be responsible for the following tasks.

a. Receive from the TSS head copies of the TSRs, OSRs, or LCDs, and assign them to the responsible supervisors. 
b. Assist each responsible supervisor in preparing TSS's facility TSR, OSR, or LCD instrument plan.

c. Ensure compliance with the TSR/OSR/LCD instrument program described herein and compliance with each instrument facility plan within the scope of that general supervisor's responsibility.

\subsection{SUPERVISORS}

TSS supervisors shall review the TSRs, OSRs, and LCDs obtained from the general supervisors and ensure that the facility manager has documented required services such as instrument identification, maintenance, scheduling, and calibration. TSS supervisors shall interface with the facility manager to clarify maintenance requirements. Supervisors shall be responsible for the following actions.

a. Assist the facility manager in identifying instruments, components, and systems requiring special labels, and ensure proper labeling to maintain configuration control.

b. Prepare lists of designated TSR, OSR, or LCD Safety System instruments with information as required on the TSR/OSR/LCD Safety System Instrument Listing form (see Appendix A).

c. Identify maintenance personnel working in or on a given facility, and provide training as directed by this document.

d. Place instrument information in the TSS Maintenance Information Data Acquisition System (MIDAS), Sect. 10, "Maintenance, Accountability, Jobs, and Inventory Control (MAJC) System" (Ref. 1) recall system for surveillance, calibration, and preventive maintenance (PM), identifying as safety or limiting condition instruments in the MAJIC data base, and removing from MAJC the TSR, OSR, or LCD designation for any instrument no longer a component of a TSR, OSR, or LCD system.

e. Maintain documentation indicating special actions or procedures needed to maintain components or systems.

f. Ensure that all work required by approved change notices originated by the facility manager, I\&C Division, or appropriate engineering section has been performed and that copies of approved change notices are filed at the shop location and supplied to the TSS TSR/OSR/LCD coordinator.

g. Supply the facility manager and TSS TSR/OSR/LCD coordinator written notification of interruptions in maintenance or calibration schedules.

h. Maintain spare parts and a spare-parts list identifying each piece of safety system equipment, and maintain in storage an adequate identified inventory to meet maintenance requirements.

i. Update MAJIC work requests to indicate instruments "on hold." 
j. Verify that all TSR, OSR, or LCD identification labels have been removed from instruments that are no longer components of a TSR, OSR, or LCD system.

k. Ensure that TSS personnel visiting a facility to conduct TSR-, OSR-, or LCD-related activities inform the facility manager or his designee before beginning each activity. Sufficient time must be allowed for facility personnel to make appropriate arrangements to accommodate the tasks.

1. Ensure that TSS personnel inform the facility manager or his designee promptly when the TSR-, OSR-, or LCD-related activity is completed and the results of the activity.

If the activity is completed after normal working hours or if facility personnel are not available, such notification shall be made the next working day. 


\section{PROCEDURES FOR DEVELOPING TECHNICAL SUPPORT SECTION TSR, OSR, OR LCD INSTRUMENT FACILITY PLANS}

\subsection{INSTRUMENT FACILITY PLANS}

The purpose of a TSS TSR, OSR, or LCD instrument facility plan is to ensure instrument identification and compliance with all surveillance specifications of the facility TSR, OSR, or LCD. The instrument facility plan shall contain the following items.

a. Approval page. This page shall be signed by the responsible TSS and facility manager's representative(s) upon completion of all initial requirements (see Appendix A).

b. Action check list. This list shall be initialed and dated by the TSS TSR/OSR/LCD coordinator upon verification of completion of required actions by responsible personnel (see Appendix A).

c. TSR/OSR/LCD Safety System instrument listing. This listing shall include identification (ID) number, description, instrument location, maintenance information file point and location, spare parts location, set point(s) and/or limit(s), preventive maintenance, and calibration and associated alarm system(s) (see Appendix A).

d. Attachments. The attachments shall contain special procedures, training documentation, TSR, OSR, or LCD instrument listing, change notices, and other information as needed. (See Appendix A for examples of supplemental information.)

\subsection{DOCUMENTATION}

Procedures for documenting TSRs, OSRs, or LCDs are listed below.

a. Scope. A copy of the TSR, OSR, or LCD as submitted by the facility manager shall be retained with the TSS TSR/OSR/LCD instrument facility plans.

b. TSR/OSR/LCD log. Each TSR, OSR, or LCD document on file shall be logged and assigned a unique identifier as outlined in the TSS procedure MMD/AADM1012

("Technical Support Department Procedure on Procedure Writing," page 1 of Appendix 1) for document numbering consistency. For example, in the TSR/OSR/LCD log identifier MMD/AOSR1010,

"MMD" indicates the Maintenance Management Documentation;

"/A" indicates an administrative category;

"OSR" is the classification code for Operational Safety Requirements; "LCD" is the classification code for Limiting Conditions Documents; and "TSR" is the classification code for Technical Safety Requirements. 
" 101 " represents the first three digits (sequentially numbered beginning with 100 ), of which the second and third digits indicate the OSR number; those lower than 10 require a leading zero (e.g., " 01 " through " 09 " for " 1 " through " 9 "); and " 0 " is the fourth (final) digit, which normally indicates the revision number or the status code (complete or incomplete); for TSRs, OSRs, or LCDs, this digit is zero.

The given example (MMD/AOSR1010) indicates the unique identifier for OSR 01 .

c. Distribution. The TSS TSR/OSR/LCD coordinator shall distribute copies of instrument facility plans and any change notices to responsible supervisors and the facility manager's representative(s).

d. Status report. A summary of the current status of TSR/OSR/LCD facilities shall be maintained by the TSR/OSR/LCD coordinator.

e. Location. Copies of TSRs, OSRs, LCDs, TSS TSR/OSR/LCD Instrument Facility Plans, TSR/OSR/LCD logs, status reports, and other pertinent information shall be filed in the office of the TSS head.

\subsection{INSTRUMENT DESIGNATION AND LABELING}

Identification and labeling of TSR, OSR, and LCD instruments located in nonhazardous environments are described in Sects. 5.3.1 and 5.3.2. An alternate method of labeling instruments located in hazardous environments is described in Sect. 5.3.3. Under no circumstances shall information on OSR labels be marked over, marked out, or changed except to strike out OSR and replace with TSR or LCD. When a change in information is required, the old label shall be removed and destroyed and a new label shall be completed and affixed to the instrument.

\subsubsection{Safety System Instrument Labeling}

Any instrument required by the facility TSR, OSR, or LCD as a safety system item shall be designated a "TSR, OSR, or LCD safety system instrument" and identified with a yellow label, Form UCN-15544 (Fig. 1a), displaying the ID number, date label is applied, and TSS TSR, OSR, or LCD number. This label is printed on self-adhesive paper with a reasonably protective surface suitable for instruments located in nonhazardous environments.

\subsubsection{Limiting Condition Instrument Labeling}

Any instrument that must be operable as a limiting condition of the facility operation shall be designated a "TSR, OSR, or LCD instrument" and identified with a green label, Form UCN-15545 (Fig. 1b), displaying the ID number, date label is applied, and TSS TSR, OSR, or LCD number. This label is printed on self-adhesive paper with a reasonably protective surface suitable for instruments located in nonhazardous environments. 

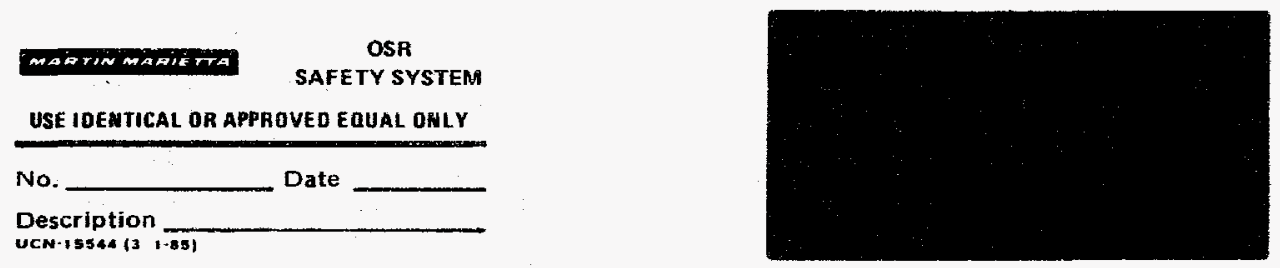

Fig. 1. Labels for TSR, OSR, and LCD instruments located in nonhazardous environments are printed in black letters on paper with a protective surface. (a) TSR, OSR, and LCD safety system instruments (yellow), Form UCN-15544; (b) TSR, OSR, and LCD instrument limiting condition (green), Form UCN-15545.

\subsubsection{Safety System and Limiting Condition Instruments in Hazardous Environments Labeling}

- This alternate method of labeling shall be used in lieu of labeling described in Sects. 5.3.1 and 5.3.2 on instruments located in hostile environments.

- The label material shall be laminated plastic capable of withstanding all environmental hazards. Two label sizes are available. The physical size of the label shall be determined by instrument location and legibility requirements.

- Labels used for TSR, OSR, and LCD safety system instruments shall have a yellow background with black letters; labels used for TSR, OSR, and LCD instruments (limiting condition) shall have a green background with white letters (Fig. 2).

- Information on the label shall include the letters "TSR," "OSR," or "LCD"; "/" (slash); letter "TS" or "TR" for TSR instruments, " $S$ " or " $R$ " for OSR instruments, or "LS" or "LR" for LCD instruments (as indicated in Sect. 5.4); and two digits indicating the TSR, OSR, or LCD number. Numbers below 10 require a leading zero (e.g., 01 through 09). Labels shown in Fig. 2 include examples of large and small labels (depending on legibility and location requirements) for OSR safety system instruments and OSR limiting condition instruments.

\subsection{INSTRUMENT IDENTIFICATION IN THE MAINTENANCE ACCOUNTABILITY, JOBS, AND INVENTORY CONTROL (MAJIC) SYSTEM}

Each instrument designated as a TSR, OSR, or LCD safety system instrument or TSR, OSR, or LCD limiting condition instrument shall be identified in the MAJC inventory by using Form UCN-10598 (Fig. 3). This information is entered in the field labeled "OSR" by using one of the following codes: 

TS00 designates TSR safety system instrument;

TR00 designates TSR instrument (limiting condition);

S00 designates OSR safety system instrument;

R00 designates OSR instrument (limiting condition);

LS00 designates LCD safety system instrument; or

LR00 designates LCD instrument (limiting condition).

The zeros represent the two digits required for the TSR, OSR, or LCD document number. Numbers lower than 10 require a leading zero (e.g., 01 through 09 , but 10 through 99 for numbers higher than 9).

\section{-OSR/S27}

COSR/S27

\section{OSR/R27}

\section{OsR/R27}

Fig. 2. Alternate labels used for instruments located in hostile environments are made of laminated plastic material to withstand all environmental hazards. (a) Yellow labels (large and small) with black lettering for TSR, OSR, or LCD safety system instruments. (b) Green labels (large and small) with white lettering for TSR, OSR, or LCD (limiting condition) instruments.

I 8 C INSTRUMENT INVENTORY

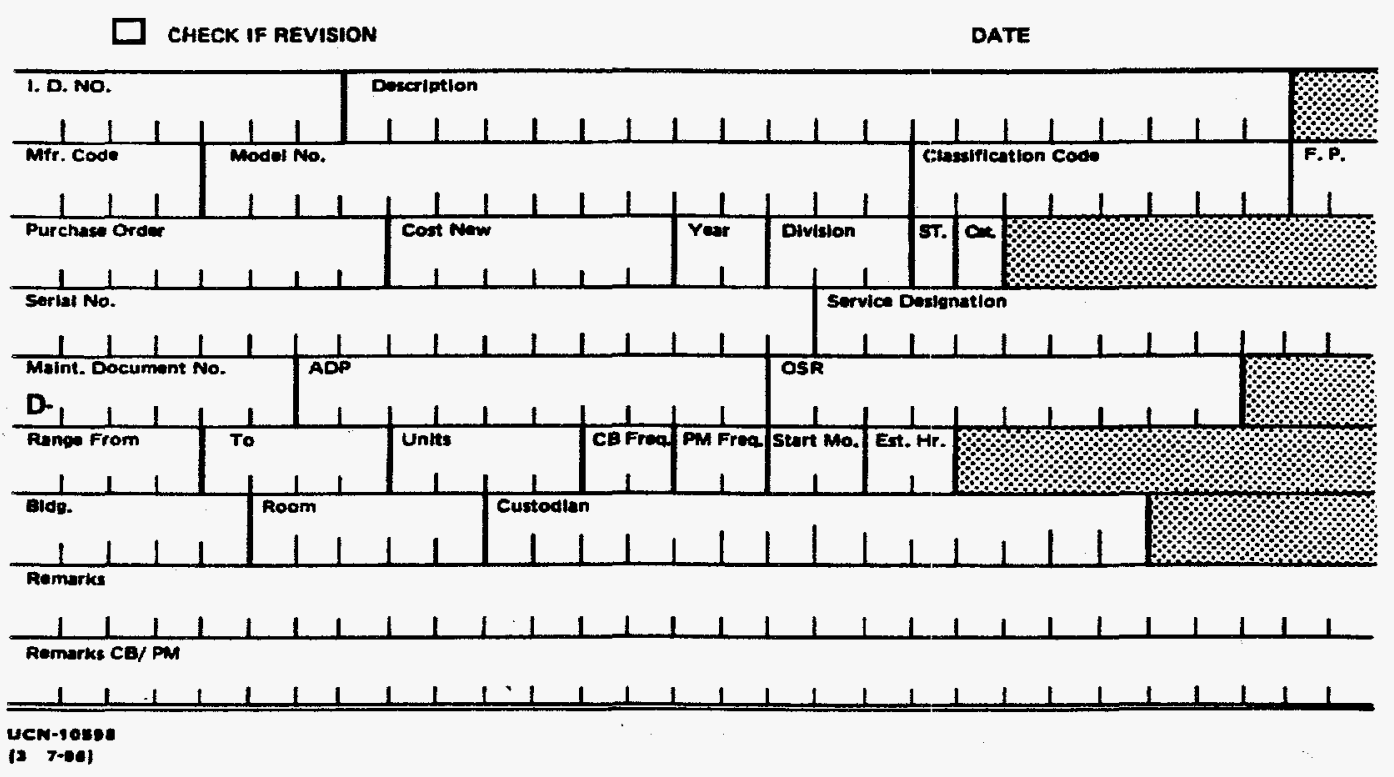

Fig. 3. Instrumentation and Controls instrument inventory, Form UCN-10598. 



\subsection{HANDLING OF INSTRUMENTS "ON HOLD"}

Instruments "on hold" are those awaiting parts to complete repair. The following requirements shall apply.

a. The work request shall remain open until the instrument is repaired.

b. Instruments "on hold" shall be identified in MAJIC with the appropriate delay code.

c. A copy of the work request shall be affixed to the instrument, or the work request number may be written on the "Out of Service" or "Hold Tag."

d. When parts are ordered on a purchase requisition specifically for an "on-hold" TSR, OSR, or LCD instrument, the purchase requisition number shall be written on the work request.

\subsection{REMOVAL OF INSTRUMENTS FROM TSR, OSR, OR LCD SERVICE}

5.6.1 No changes shall be made to TSR-, OSR-, or LCD-identified instrumentation without prior approval from the facility manager via an approved configuration control change request.

5.6.2 Each instrument removed from TSR, OSR, or LCD service as a result of equipment upgrade, excessive maintenance, or changes to the safety document shall have all identification (yellow or green label) removed. Additionally, MAJIC shall be immediately updated to indicate that these instruments are no longer required. 


\section{TRAINING}

The TSS training manual was designed to meet the requirements of DOE Order 5480.20

"Personnel Selection, Qualification, Training, and Staffing Requirements at DOE Reactor and Nonreactor Nuclear Facilities." This program ensures that TSS personnel meet the requirements for performing maintenance in nonreactor nuclear facilities. Training is. performed and documented for each facility. A copy of the documenting form, "Qualified I\&C Division Facility Maintenance Personnel,"' is shown in Appendix A. 


\section{TSR, OSR, AND LCD REVIEW PROCEDURES}

TSS instrument facility plans for nonreactor nuclear facilities with identified TSRs, OSRs, or LCDs are reviewed annually, consistent with the requirements of Energy Systems and DOE procedures.

\subsection{INSTRUMENT FACILITY PLAN REVIEW OBJECTIVES}

The objectives of the TSS TSR/OSR/LCD instrument facility plan reviews are to ensure that

a. changes in facility operation affecting TSS's responsibility are systematically and regularly identified,

b. maintenance personnel working in or on the facility are regularly identified and trained as required by applicable DOE procedures and the TSS training program for nonreactor nuclear facilities,

c. scheduled maintenance and surveillance plans are followed as outlined in the facility safety document, and

d. proper documentation is maintained on file for each facility and all TSS personnel involved in that facility.

\subsection{ANNUAL REVIEW RESPONSIBILITIES}

TSS supervisors and the TSS TSR/OSR/LCD coordinator shall perform the activities outlined below.

\subsubsection{TSS Supervisors}

TSS supervisors shall

a. identify TSS personnel working in or on nonreactor nuclear facilities;

b. inventory TSR, OSR, or LCD instruments and spares for approved markings (i.e., green or yellow labels, as appropriate) and documentation;

c. review maintenance procedures and access requirements with instrument technicians and engineering technologists;

d. ensure proper documentation in MAJIC for TSR, OSR, or LCD instruments, using I\&C instrument inventory Form UCN-10598;

e. supply written notification to the appropriate facility supervisor and the TSR/OSR/LCD coordinator of interruptions in maintenance and calibration schedules; and 
f. provide documentation of listed actions to the TSR/OSR/LCD coordinator, as outlined in the facility review notification.

\subsubsection{TSS TSR/OSR/LCD Coordinator}

The TSS TSR/OSR/LCD coordinator shall

a. ensure that copies of TSR, OSR, and LCD instrument facility plans, facility reviews, training records, and memoranda are maintained in TSS files;

b. interface with the facility manager, OORFS, and TSS personnel on any developments concerning TSRs, OSRs, or LCDs;

c. review each instrument facility plan, and generate a facility review report based on current information;

d. notify the appropriate facility manager of any needs for facility-specific training of TSS personnel;

e. schedule reviews of TSRs, OSRs, LCDs, and instrument facility plans with the general supervisors and maintenance supervisors; and

f. inform TSS staff and appropriate facility manager upon completion of a facility review. 


\section{REFERENCE}

1. C. T. Stansberry, S. M. Odom, and C. D. Martin, Maintenance Information Data Acquisition System (MDAS), ORNL/TM-11287/Rev. 1, Oak Ridge National Laboratory, Oak Ridge, Tenn., September 1989. 


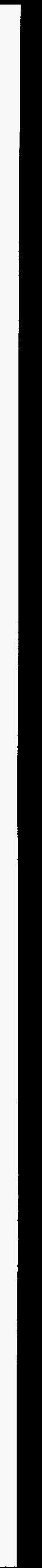


Appendix A

EXAMPLES OF FORMS USED FOR INSTRUMENT FACILITY PLAN, MAINTENANCE PERSONNEL ASSIGNMENTS, AND

SAFETY INSTRUMENT LISTING FOR OSRs

(Forms are changed as needed to identify TSR or LCD.) 



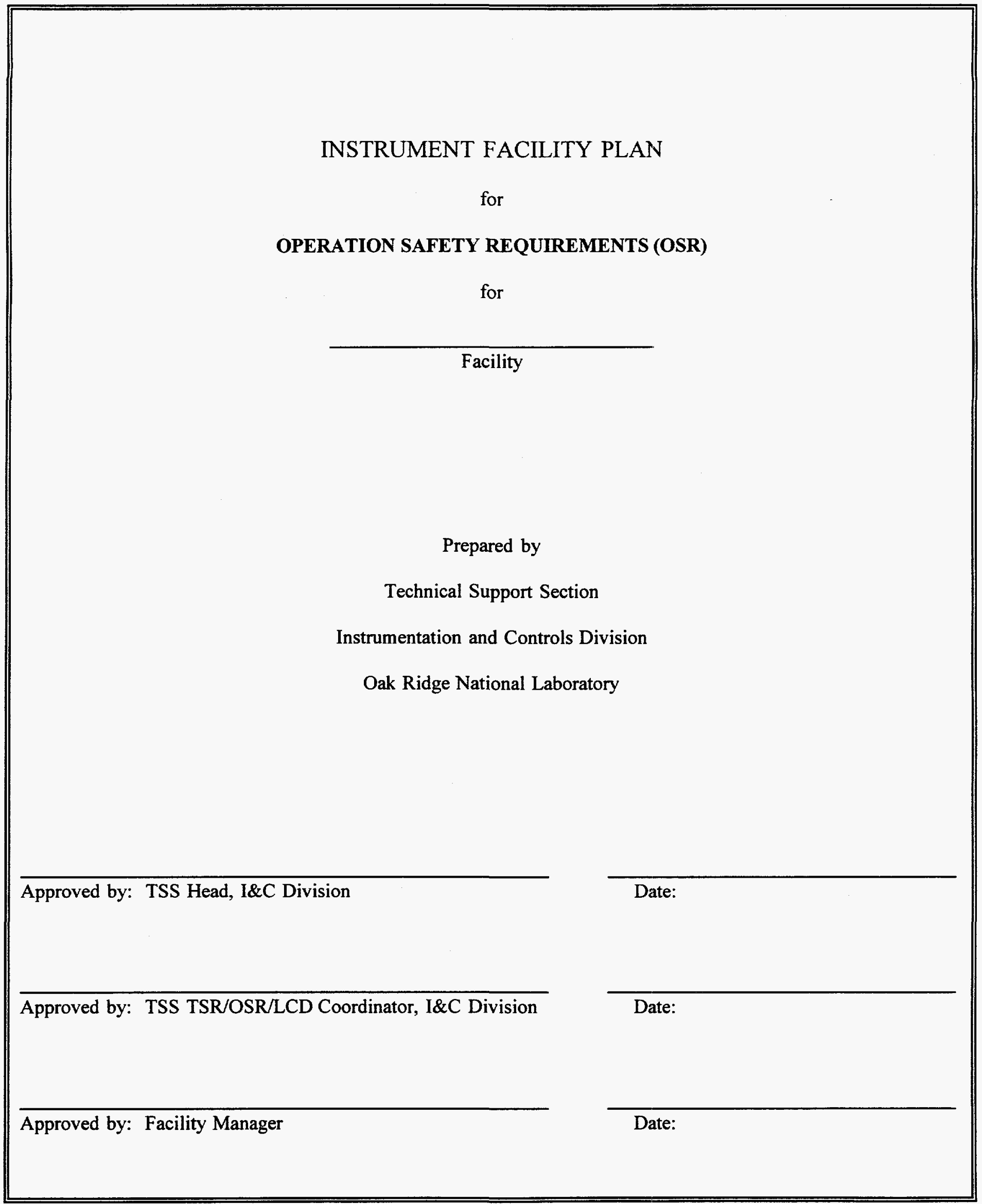




\section{INTRODUCTION}

The following Facility Plan and supporting documents from the Technical Support Section (TSS) of the Instrumentation and Controls (I\&C) Division ensure that the requirements of the following DOE Orders; Martin Marietta Energy Systems, Inc. (Energy Systems), Standard; and ORNL, I\&C TSS, and facility procedures are addressed:

1. Energy Systems Standard ESS-FS-201,

2. ORNL Standard Practice Procedure X-ESH-1,

3. ORNL Facility Safety Procedure FS-2.0,

4. Facility OSR, and

5. I\&C TSS ORNL/TM-10846/R2.

Supporting documents include the facility instrument listing, safety instrument listing (if applicable), listing of TSS maintenance personnel assigned to the OSR, and a checklist detailing actions taken in identifying OSR instruments and maintenance personnel.

Instruments identified in the OSR have been entered in the TSS maintenance database, MIDAS (Maintenance Information and Data Acquisition System), for maintenance tracking and surveillance recall as identified in the OSR.

Documentation of required training for personnel assigned to the OSR is filed in the I\&C TSS located in Building 3500 and entered in the TSS Training Database. Training conforms to requirements of DOE Order 5480.20 (Personnel Selection, Qualification, Training, and Staffing Requirements of DOE Reactor and Non-Reactor Nuclear Facilities). 
TECHNICAL SUPPORT SECTION OSR FACILITY PLAN CHECKLIST

Action
1. OSR documentation received from the facility supervisor
(section head).
2. Assign TSS OSR identification number and initiate Facility
Plan; open new facility file in Building 3500 (coordinator).
3. Distribute OSR to responsible supervisor(s) for review (section
head).
4. Review OSR with responsible supervisor(s) (coordinator).
5. Identify facility instrumentation that will be designated critical;
tag OSRS Safety System with a yellow sticker and OSRR
instruments with a green sticker (TSS supervisor).
6. Prepare listing of designated OSR Safety System instruments
(if applicable) by ID number with pertinent information per
attachment [supervisor(s)].
7. Identify and label spare parts associated with OSR Safety
Systems per attachment [supervisor(s)].
8. Enter instruments into MAJIC for scheduled recall on
calibration and programmed maintenance (PM) and identify as
a Safety-Related Instrument per attachment [supervisor(s)].
9. Provide guidance for action concerning any unusual calibration
or maintenance procedure unique to this OSR facility that are
to be included in the TSS OSR Facility Plan per attachment
[supervisor(s)].
11. Submit final draft of Facility Plan for approval by TSS staff
and facility supervisor (coordinator).

Note: Changes in procedures, instrumentation, or requirements should be brought to the attention of the TSS OSR coordinator.

*In collaboration with facility supervisor(s). 


\begin{tabular}{|l|c|c|}
\hline$i_{\&} c$ & QUALIFIED I\&C DIVISION & Instrumentation \& Controls \\
\hline
\end{tabular}

Facility

The following Technical Support Section personnel are authorized to perform maintenance and calibration on instruments in this facility. The following items have been addressed:

1. Technicians have demonstrated competence in performing maintenance and calibration on these or similar instruments.

2. Technicians have been provided with names and locations of approved contact persons for this facility.

3. The following technicians have read the Operational Safety Requirements (OSR) and are aware of instrument or system requirements and maintenance procedures which may exist for this facility. 
DATE

\begin{tabular}{|c|c|c|c|c|c|c|c|c|}
\hline M NUMBER & DESCRIPTION & $\begin{array}{l}\text { instrules } \\
\text { LOCATION } \\
\end{array}$ & $\begin{array}{l}\text { MAINTENANCE } \\
\text { INFORATION } \\
\text { LOCATION } \\
\end{array}$ & $\begin{array}{c}\text { SPARE } \\
\text { PARTS } \\
\text { LOCATION }\end{array}$ & $\begin{array}{c}\text { SET POINTS } \\
\text { LIMITS }\end{array}$ & $\begin{array}{c}\text { CAL } \\
\text { FREQ. }\end{array}$ & $\begin{array}{c}\text { PM } \\
\text { FREQ }\end{array}$ & $\begin{array}{c}\text { ASSOCIATED } \\
\text { ALARMS }\end{array}$ \\
\hline & & & & & & & & \\
\hline & & & & & & & & \\
\hline & & & & & & & & \\
\hline & & & & & & & & \\
\hline & & & & & & & & \\
\hline & & & & & & & & \\
\hline & & & & & & & & \\
\hline & & & & & & & & \\
\hline & & & & & & & & \\
\hline & & & & & & & & \\
\hline & & & & & & & & \\
\hline & & & & & & & & \\
\hline & & & & & & & & \\
\hline & & & & & & & & \\
\hline & & & & & & & & \\
\hline & & & & & & & & \\
\hline & & & & & & & & \\
\hline & & & & & & & & \\
\hline & & & & & & & & \\
\hline
\end{tabular}



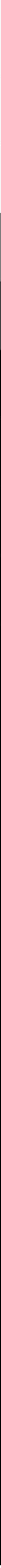

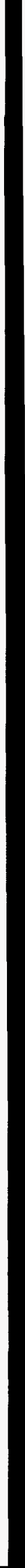




\section{INTERNAL DISTRIBUTION}

1. B. P. Adkisson

2. G. T. Alley

3-16. K. L. Allison

17. M. E. Boren

18. P. R. Cotten

19. B. C. Davis

20. J. C. Glowienka

21. J. L. Hammontree

22. R. A. Hess

23. J. M. Jansen

24. M. W. Kohring

25. C. W. Kunselman

26. W. L. Marsh

27. D. W. McDonald

28. G. N. Miller
29. S. M. Odom

30. J. E. Payne

31. D. G. Prater (QAS)

32. R. T. Roseberry

33. C. T. Stansberry

34. R. A. Vines

35. J. W. White

36. ORNL QA Manager

37. ORNL Patent Section

38-39. Central Research Library

40. Y-12 Document Reference Section

41-42. Laboratory Records Department

43. Laboratory Records ORNL-RC

44. I\&C Division Publications

\section{EXTERNAL DISTRIBUTION}

45-46. D. C. Queen, DOE-ORO, Y-12, Oak Ridge, TN 37831

47-48. R. E. Williams, DOE-ORO, Y-12, Oak Ridge, TN 37831

49. Assistant Manager for Energy Research and Development, DOE-ORO, P.O. Box 2001, Oak Ridge, TN 37831-8600

50-51. Office of Scientific and Technical Information, P.O. Box 62, Oak Ridge, TN 37831 
